\title{
Assessment of Bleached and Unbleached Jute Yarn with Various Dyes and Parameters
}

\author{
Shamim Alam* \\ Department of Textile Engineering, Southeast University, Bangladesh
}

*Corresponding author: : Shamim Alam, Department of Textile Engineering, Southeast University, 251/A \& 252, Tejgaon I/A, Dhaka1208, Bangladesh

submission: 眥 December 12, 2017; Published: 涀April 04, 2018

\begin{abstract}
This project deals with the studies on dyeing behavior of bleached and unbleached jute yarn dyed with different dyes as well as assessment of different quality parameters like as effect of different color fastness properties, Absorbency and Weight loss. In this research work Reactive dyes (orange), Acid dyes (red), Basic dyes (yellow) and direct dyes (blue) were used. Lab dyeing machine and other fastness machines (To analyze Color Fastness to wash and Colorfastness to rubbing) were used to conduct this research work. It was found that bleached yarn had higher depth of shade and better fastness properties under the same dye concentration. Among all the dyes reactive dyes showed the better fastness property.
\end{abstract}

Keywords: Jute yarn; Reactive dye; Acid dye; Basic dye; Direct dye; Fastness properties

\section{Introduction}

Jute is a cellulosic fiber. Jute is composed of $65 \%$ cellulose and $35 \%$ natural waxes, oils and cements (lignin). Jute, a vegetable fiber that can be spun into sackcloth, used to be the "golden fiber" of Bangladesh [1]. It brought much need foreign income to the impoverished nation. But it lost its luster in the 1986 after different synthetic materials were introduced. Diversified jute products are becoming more and more valuable to the customer today. Among these are espadrilles, soft sweeter \& cardigans, floor covering, home textiles, high performance technical textiles, geo textiles \&many more products are becoming familiar jute products [2].

Jute is mostly dyed with basic dye because it has natural affinity to this dye. As a Cellulosic fiber, jute may have to well respond to Reactive dye. The reactive dyes offer a wide range of dyes with varying shades, fastness, and costs with high brilliancy, easy applicability and reproducibility. In case of dyeing of jute with reactive dyes, anionic dyes react with functional group (hydroxyl groups) of the fiber by either substitution or addition reactions $[3,4]$. Many studies have been devoted to improve the substantively of cellulosic fiber for reactive dyes. A few efforts were made to improve the light fastness [5]. Different quality parameters like as color fastness to wash, Rubbing fastness, Absorbency and Weight loss were carried out in this study. So in this work it was made a comparative study of fastness properties and depth of shade of dyed jute yarn with Acid, Direct, Basic and Reactive dye with same dye concentration (1.5\%). which is expressed as shade\%. As depth of shade and fastness properties of dyed textile materials are very important factor that's why in this study it was identified that, which dyes shows better depth of shade and fastness properties.

\section{Materials and Methods}

\section{Materials}

Yarn: Bleached and unbleached yarn was used to complete this research work. 200gm jute yarn was collected from local market in Dhaka, Bangladesh where 100gm is $\mathrm{H} 2 \mathrm{O} 2$ bleached and 100gm non Bleached [6,7].

Dyes, chemicals and auxiliaries: There are four dyes i.e. reactive dye (Remazol, Ev-orange D2R), direct dye, acid dye, basic dye were used here. All the dyes used in this study were collected from the laboratory of Southeast University. Other chemicals such as Pearlavin NDA, RSA (Parlavin SRS, Supplier- DR. petty), d Ladiquest (supplier-Archroma), sodium carbonate (Na2Co3) and sodium chloride $(\mathrm{NaCl})$ were also used.

\section{Methods}

Figure 1 shows the study process with lab dyeing machine, different fastness tester (James Heal UK Crock master for rubbing fastness test and lab dyeing machine Gyro wash for wash fastness test) [8]. Here same recipe was followed for both bleached and unbleached jute yarn. 


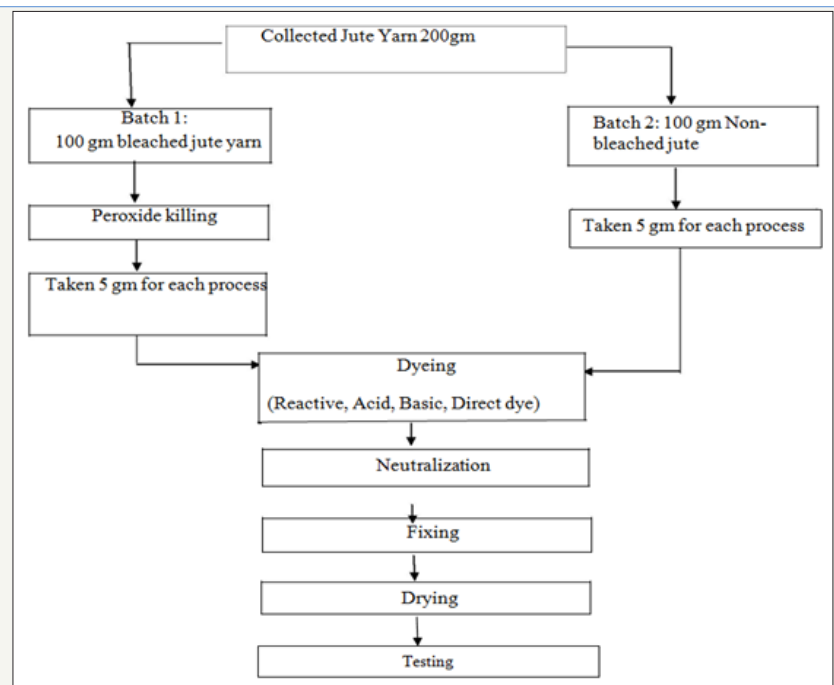

Figure 1: The test process with bleached and unbleached jute yarn.

Table 1: The recipe for scouring and bleaching.

\begin{tabular}{|c|c|}
\hline Detergent & $\mathbf{1 g m} / \mathbf{L}$ \\
\hline $\mathrm{NaOH}$ & $1 \mathrm{gm} / \mathrm{L}$ \\
\hline $\mathrm{H} 2 \mathrm{O} 2$ & $5 \mathrm{gm} / \mathrm{L}$ \\
\hline Soda ash (Na2CO3) & $5 \mathrm{gm} / \mathrm{L}$ \\
\hline Wetting agent & $1 \mathrm{gm} / \mathrm{L}$ \\
\hline Sequestering agent & $1 \mathrm{gm} / \mathrm{L}$ \\
\hline Time & $30 \mathrm{~min}$ \\
\hline Temp & $90{ }^{\circ} \mathrm{C}$ \\
\hline $\mathrm{pH}$ & 10.5 \\
\hline $\mathrm{M}: \mathrm{L}$ & $1: 10$ \\
\hline
\end{tabular}

Scouring and bleaching of jute yarn: Table 1 shows parameters for the scouring and bleaching. According to the following recipe, jute yarn was bleached and make ready for the dyeing.

Dyeing of jute yarn with various dyes: $1.5 \%$ dye concentration were applied on bleached and unbleached jute yarn. Then the yarns were dyed by using lab dyeing machine where the liquor ratio was 1:10 for the mentioned dye concentration see Table 2. During dyeing, standard methods were followed as prescribed by the manufacturers. The $\mathrm{pH}$ of the dye bath was adjusted by soda ash and acetic acid for different dyes. Then dyeing was completed according to the following recipes, time, temperature and $\mathrm{pH}$ [9]. After that we took the fabric for after treatment. Then neutralization (by $1 \mathrm{~g} / \mathrm{L}$ acetic acid and soda ash), soap wash (by $1 \mathrm{~g} / \mathrm{L}$ detergent), hot wash, and cold wash were done sequentially. Then fabric was squeezed and dried.

Table 2: Recipe used for dyeing.

\begin{tabular}{|c|c|c|c|c|}
\hline Particulars & By Reactive Dyes & By Direct Dyes & By Basic Dyes & By Acid Dyes \\
\hline Dyes & $1.5 \%$ & $1.5 \%$ & $1.5 \%$ & $1.5 \%$ \\
\hline Glubar Salt & $60 \mathrm{~g} / \mathrm{L}$ & $20 \mathrm{~g} / \mathrm{L}$ & $20 \mathrm{~g} / \mathrm{L}$ & $20 \mathrm{~g} / \mathrm{L}$ \\
\hline Soda & $15 \mathrm{~g} / \mathrm{L}$ & $3 g / L$ & $\mathrm{X}$ & $\mathrm{x}$ \\
\hline NDA & $1 \mathrm{~g} / \mathrm{L}$ & $1 \mathrm{~g} / \mathrm{L}$ & $1 \mathrm{~g} / \mathrm{L}$ & $1 \mathrm{~g} / \mathrm{L}$ \\
\hline M.F (Ladiquest) & $1 \mathrm{~g} / \mathrm{L}$ & $1 \mathrm{~g} / \mathrm{L}$ & $1 \mathrm{~g} / \mathrm{L}$ & $1 \mathrm{~g} / \mathrm{L}$ \\
\hline Fixing agent & $\mathrm{x}$ & $1 \mathrm{~g} / \mathrm{L}$ & $\mathrm{X}$ & $\mathrm{X}$ \\
\hline Acetic Acid & $\mathrm{X}$ & $\mathrm{x}$ & $1 \mathrm{~g} / \mathrm{L}$ & $1 \mathrm{~g} / \mathrm{L}$ \\
\hline $\mathrm{PH}$ & 10.5 & 9 & 4.5 & 4.5 \\
\hline Time & $60 \mathrm{~min}$ & $45 \mathrm{~min}$ & $45 \mathrm{~min}$ & $45 \mathrm{~min}$ \\
\hline Temperature & $60{ }^{\circ} \mathrm{C}$ & $90^{\circ} \mathrm{C}$ & $80^{\circ} \mathrm{C}$ & $80^{\circ} \mathrm{C}$ \\
\hline Sample weight & \multicolumn{4}{|c|}{$5 \mathrm{gm}$} \\
\hline $\mathrm{M}: \mathrm{L}$ & \multicolumn{4}{|c|}{$1: 10$} \\
\hline
\end{tabular}




\section{Different quality parameters assessment methods}

Weight loss test: The weight of the gray jute yarn and bleached jute yarn were measured using electric balance. Then calculate the weight loss in percentage [10]. By analyzing weight loss it will be understand that how much impurities are removed from bleached jute yarn.

Absorbency test: drop test: A drop of water was fallen on the bleached and unbleached jute yarn with a pipette and time in second is measured unit the water drop is absorbed. For this test $5 \mathrm{~cm}$ Sample was taken and observed whether water drop was absorbed within $5 \mathrm{sec}$ or not. As dye take-up\% depends on the absorbency of the textile fibre so this drop test was taken.

Color fastness to wash: ISO standards 105-C02 method was followed for wash fastness test [11].

Color fastness to rubbing: ISO 105-C02 method was followed for rubbing fastness test and James Heal UK Crock master was used here to complete the test. Jute bleached and unbleached sample $(14 \mathrm{cmX} 5 \mathrm{~cm})$ was clamped in the crock master and $(5 \mathrm{cmX} 5 \mathrm{~cm})$ of the white cotton fabric was attached with the upper finger of the Crock master [12]. Test was carried out for bleached and unbleached sample both in wet and dry condition. Then results were evaluated by using grayscale.

\section{Results and Discussion}

\section{Analysis of weight loss}

The weight of unbleached jute yarn was $100 \mathrm{gm}$. after bleaches it was found $93.33 \mathrm{gm}$. So, the weight loss (\%) is $6.67 \%$. As Jute is a cellulosic fiber and it contains natural impurities that's why it loses its weight by the process of Bleaching. Here is the graphical representation of weight of unbleached and bleached jute yarn in the Figure 2.

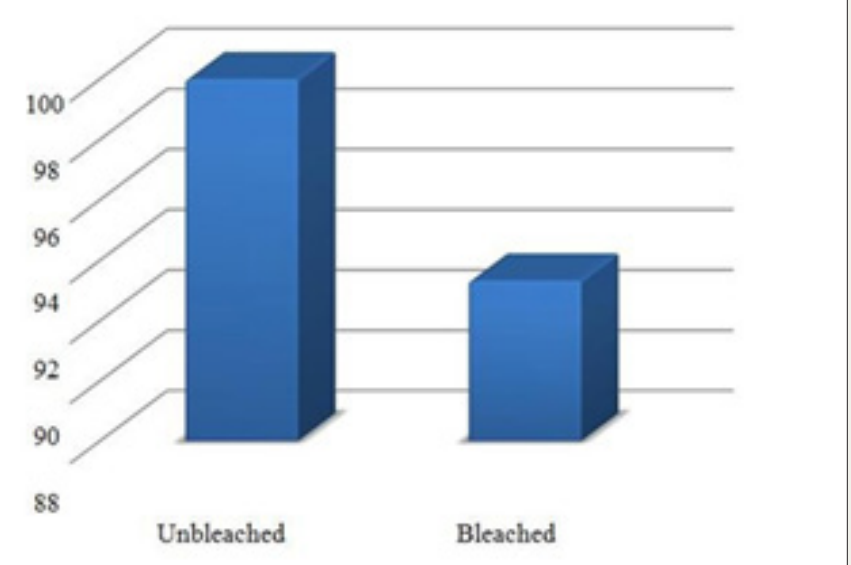

Figure 2: Weightof unbleached and bleached jute yarn.

\section{Analysis of absorbency}

Bleached jute yarns absorbed water within $5 \mathrm{sec}$, but unbleached jute yarn did not absorbed due to natural impurities such as oil, wax, fats, grease etc present in the jute yarn. As combined scouring and bleaching was done in this study so oil, wax, fats, grease and natural gray colors were removed from bleached jute yarn.

\section{Analysis of different color fastness}

Color fastness to wash: Color fastness to wash results was analyzed by two scale i.e. gray for color change and gray scale for staining. Color change results for bleached and unbleached jute yarn are placed in Figure 3. It was observed from the Figure 2 bleached yarns showed the better fastness properties than unbleached yarn. It was also found that reactive, direct and basic dyes showed good fastness properties than acid dye. Color staining results for bleached and unbleached jute yarn are placed in Figure 4. Obviously bleached yarn showed the better fastness than unbleached for all dyes. Among all the dyes reactive dyes have the better fastness properties.

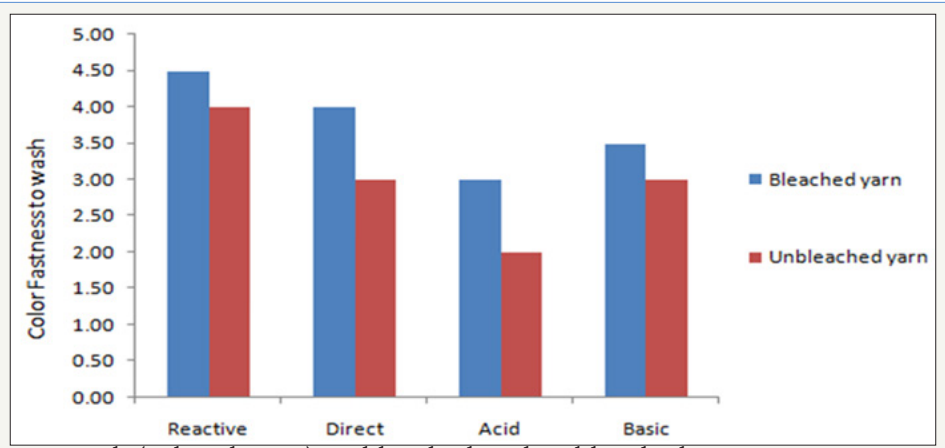

Figure 3: Effect of color fastness to wash (color change) on bleached and unbleached yarn. 


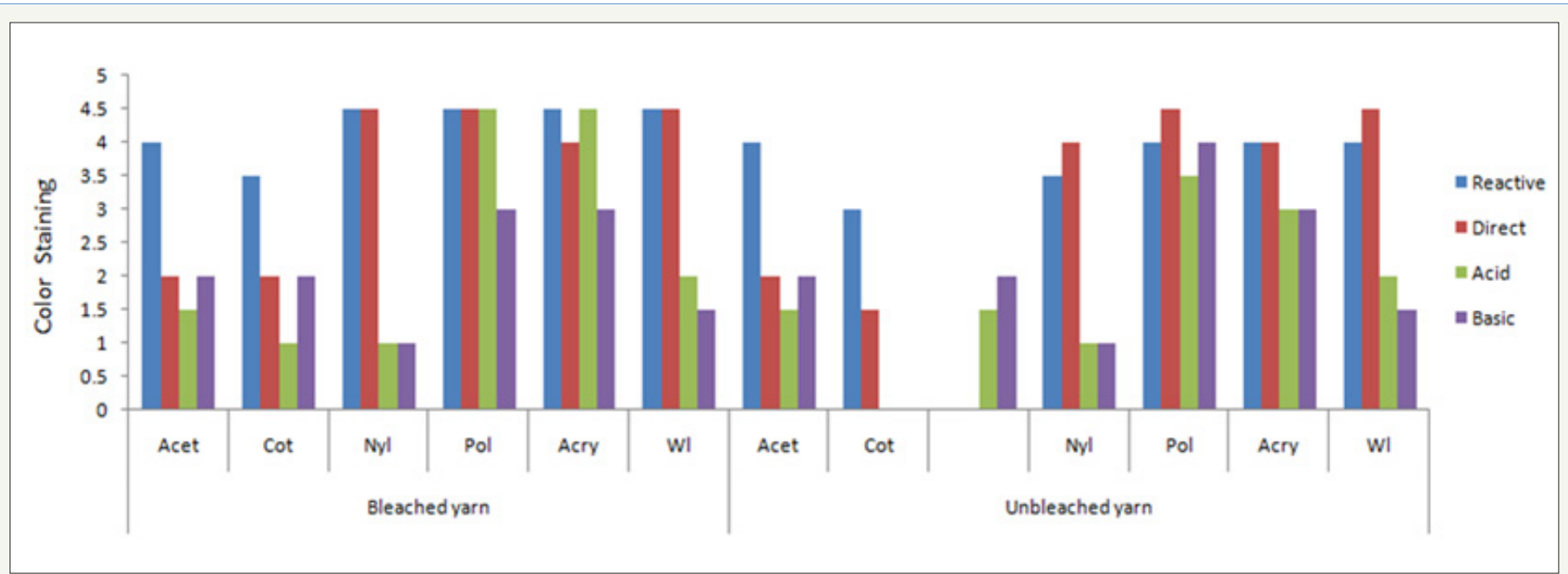

Figure 4: Effect of color fastness to wash (color Staining) on bleached and unbleached yarn.

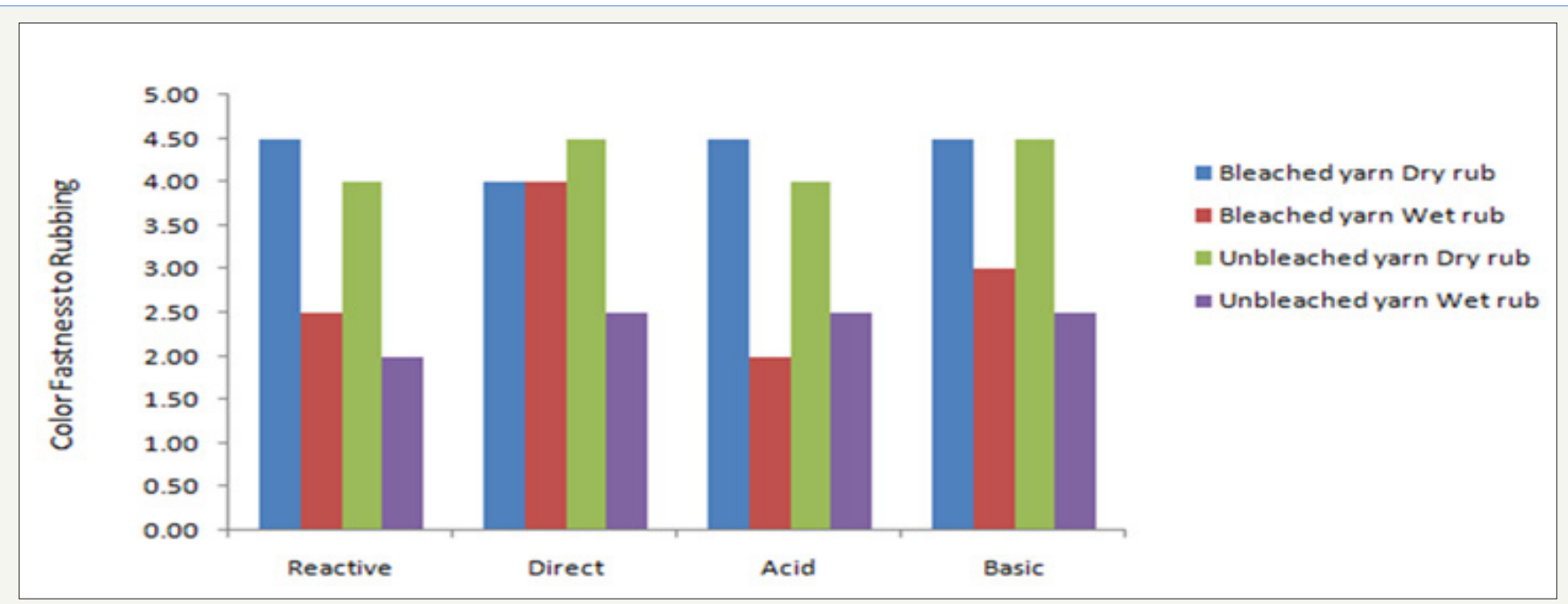

Figure 5:Effect of color fastness to rubbing.

Color fastness to rubbing: Color fastness to rubbing results are placed in Figure 5, where it was found that better rubbing fastness in dry condition in compare to wet condition for both bleached and unbleached yarn. Besides this bleaches yarn have the very good to excellent fastness in dry condition for all types of dyes.

\section{Conclusion}

This project work was planned to compare dyeing behavior of bleached and unbleached jute yarn and assessment of different quality parameters i.e. color fastness to wash, Rubbing fastness, Absorbency and Weight loss that are being done in textile industries. Different test results were included in this paper in the results and discussion section. In this research work it was found that, in case of bleached jute yarn brighter shades were obtained than unbleached jute yarn dyeing with different dyes. Among them reactive dyes showed the better fastness properties. As we know jute fiber contains lignin in the composition of this fiber so it should remove before dyeing or other process otherwise lignin will deteriorate the subsequence process. At last it was concluded that there is a considerable effect between the bleached and unbleached jute yarn and different fastness properties was also obtained for different dyes.

\section{References}

1. Rahman Bhuiyan MA, Abu S, Bashar MM, Haque P, Hannan MA_(2013) Novel approach of dyeing jute fiber with reactive dye after treating with chitosan. Open Journal of Organic Polymer Materials 3(4): 5.

2. Sharfun NA, Afsar AM (2017) Chemical modification of jute fibers for improving its hydrophobicity and dyeability with reactive dyes. World Journal of Research and Review 5(4): 62-69.

3. Sarwar Z, Azeem A, Munir U, Abid S (2017) Direct dyeing of jute: effect of cationic treatments on color fastness. Journal of Textile Science \& Engineering 7(2): 1-4.

4. Hickman WS (1995) Preparation in cellulosic dyeing. In: Society of Dyers and Colorists, UK, pp. 81-151.

5. Aspland JR (1992) Practical application of reactive dyes in textile chemist and colorist 24(6): 35-40.

6. Broadbent $\mathrm{AD}$ (2001) Basic principles of textile coloration. In: Society of Dyers and Colorists, UK, pp. 232-257.

7. Shore J (1995) Dyeing with reactive dyes. In: Cellulosic Dyeing. Pp. 189245. 
8. Broadbent AD (2001) Basic principles of textile coloration. In: Society of Dyers and Colorists, UK, pp. 335-345.

9. Holme I (1967) Fibre physics and chemistry in relation to coloration. Coloration Technology 1(1): 31-34.

10. Haque ANMA (2014) Influence of electrolyte and liquor ratio on exhaustion and color coordinates of cotton fabric dyed with mono functional and bi-functional reactive dyes. Borneo Science 34: 27-33.
11. (2016) Textiles-Tests for color fastness-Part C04: Color fastness to washing.

12. (2016) Textiles-Tests for color fastness-Part X12: Color fastness to rubbing.

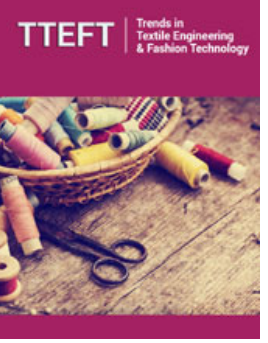

Trends in Textile Engineering \& Fashion Technology

\section{Benefits of Publishing with us}

- High-level peer review and editorial services

- Freely accessible online immediately upon publication

- Authors retain the copyright to their work

- Licensing it under a Creative Commons license

- Visibility through different online platforms 